\title{
PEMODELAN MATEMATIKA MASALAH LINGKUNGAN UNTUK MENINGKATKAN KESADARAN PELESTARIAN LINGKUNGAN GABI SISWA SMP
}

\author{
Maria Wilda Malo', Egidius Gunardi ${ }^{2}$, dan Elisa Maria C. Situmorang ${ }^{3}$ \\ ${ }^{1,2,3}$ Pendidikan Matematika FKIP Universitas Sanata Dharma
}

\begin{abstract}
Mathematical modeling of environmental problems is one of the means in an effort Mathematizing reality as well as to draw attention to the importance of environmental preservation. The purpose of this research to improve students skills in mathematical modeling and awareness of environmental preservation. This research was conducted at St. Aloysius Turi junior high school students of class VII. This type of research is descriptive qualitative approach to discovery learning. The study begins by providing questions to each group, and then analyze the results of the students' work to determine the level of understanding and the ends on reflection of environmental protection. The data analysis by comparing the results of the work between the groups, interviews and reflections from students. The results show that through modeling that was obtained they were able to determine the increased amount of garbage for the next 2025 years. Modeling of environmental issues also have an impact on increasing students' awareness to environmental conservation.
\end{abstract}

Keywords: modelling mathematic; discovery learning; enviromental conservation.

\begin{abstract}
Abstrak
Pemodelan matematika masalah lingkungan adalah salah satu sarana dalam upaya mematematikakan realita serta untuk menyadarkan siswa akan pentingnya pelestarian lingkungan hidup.Tujuan penelitiaan ini adalah meningkatkan kemampuan siswa dalam memodelkan matematika dan kesadaran terhadap pelestarian lingkungan. Penelitian ini dilakukan pada siswa SMP Santo Aloysius Turi kelas VII. Jenis penelitian yang digunakan adalah deskriptif kualitatif dengan pendekatan discovery learning. Penelitian diawali dengan memberikan soal kepada setiap kelompok, kemudian menganalisis hasil pekerjaan siswa untuk mengetahui tingkat pemahaman dan berakhir pada refleksi terhadap upaya pelestarian lingkungan hidup. Analisis data dilakukan dengan membandingkan hasil pekerjaan antar kelompok dan dari hasil wawancara serta refleksi dari siswa. Hasilnya menunjukkan bahwa melalui pemodelan yang di peroleh mereka mampu mengetahui jumlah peningkatan sampah untuk 2025 tahun mendatang. Pemodelan masalah lingkungan ini juga berdampak pada meningkatnya kesadaran siswa terhadap pelestarian lingkungan.
\end{abstract}

FKIP Universitas Sanata Dharma

Email: mariawildamalo@gmail.com
(C)2017 Universitas Islam Negeri Walisongo

ISSN: 2088-7868, e-ISSN 2502-5708 
Kata kunci: Pemodelan matematika, discovery learning, pelestarian lingkungan.

\section{PENDAHULUAN}

Mengajar matematika dalam hubungan dengan dunia nyata adalah masalah internasional (dalam Mathematical Modelling : A Way Of Life, Yanagimoto, Akira dan Tennoji Jr; 2003; 54). Sejauh pegalaman peneliti, pembelajaran matematika di Indonesia belum sepenuhnya menekankan pembelajaran matematika dalam hubungan dengan masalah dunia nyata. Soal matematika yang dihadapi oleh seseorang seringkali tidak mengarahkan ke permasalahan lingkungan sekitar. Kesadaran akan hal inilah yang mendorong peneliti untuk mengembangkan pembelajaran matematika yang berhubungan dengan masalah lingkungan. Dengan kegiatan ini, siswa dapat berlatih untuk berpikir analisis dan mencoba memecahkan problema yang dihadapi sendiri. Kebiasaan ini akan ditransfer dalam kehidupan sehari - hari yakni kesadaran siswa akan pentingnya menjaga kelestarian lingkungan. Pada penelitian ini, siswa diberi soal yang berkaitan dengan masalah sampah kantong plastik di Indonesia. Hal ini bermanfaat bagi pengembangan keterampilan berpikir siswa agar dapat menemukan cara yang tepat untuk memodelkan masalah sampah kantong plastik dan untuk meningkatkan kesadaran siswa akan pelestarian lingkungan hidup.

\section{METODE PENELITIAN}

Jenis penelitian yang digunakan adalah deskriptif kualitatif dengan pendekatan discovery learning. Subyek penelitian adalah siswa SMP Santo Aloysius Turi Kelas VII sebanyak 6 orang dengan kode responden S1, S2, S3, S4, S5, dan S6.

Pengambilan data dalam penelitian ini dilakukan dua kali; pada pertemuan pertama, peneliti melakukan ujicoba istrumen penelitian untuk melihat tingkat pemahaman siswa SMP terhadap soal permasalahan lingkungan. Pada pertemuan kedua yaitu proses penelitian, peneliti membagikan LKS kepada siswa yang berisikan berita tentang masalah jumlah sampah kantong plastik di Indonesia. Dari berita tersebut, siswa diminta memodelkan masalah tersebut ke dalam pemodelan matematika dan dikembangkan pertanyaannya untuk memprediksi jumlah kantong plastik yang tidak di daur ulang pada tahun 2025. Melalui hal tersebut peneliti dapat mengetahui 
kemampuan siswa dalam memodelkan masalah lingkungan ke dalam pemodelan matematika. Bahan penelitian yang digunakan adalah lembar kerja siswa, foto.

Pada penelitian ini, data dianalisis dari hasil kerja siswa, wawancara dan observasi. Tujuan dari wawancara adalah untuk mengetahui pendapat siswa mengenai berita penggunaan sampah plastik di Indonesia dan untuk mengetahui kesulitan siswa dalam menyelesaikan soal. Selain itu juga, wawancara digunakan untuk mengetahui niat siswa dalam upaya mengurangi sampah plastik. Sedangkan observasi dilakukan selama proses penelitian untuk mengetahui cara siswa dalam menyelesaikan LKS.

\section{HASIL DAN PEMBAHASAN}

Dalam penelitian ini, peneliti mengelompokkan siswa menjadi 2 kelompok yang terdiri dari 3 siswa dalam satu kelompok. Setiap kelompok berdiskusi untuk menyelesaikan soal tentang masalah sampah kantong plastik di Indonesia seperti pada LKS di atas. Hasilnya adlah sebagai beriku: .

Kelompok pertama (S1, S2, dan S3) menyelesaikan LKS dengan menjelaskan arti dari kalimat lebih dari 1 juta kantong plastik digunakan dalam satu menit yaitu memisalkan masyarakat Indonesia menggunakan 1.500.000 dalam setiap menitnya. Ide awal untuk menyelesaikan permasalahan di artikel adalah menghitung banyaknya menit dalam 1 hari, kemudian menghitung banyaknya menit dalam 1 tahun dan hasilnya seperti pada gambar di bawah ini.

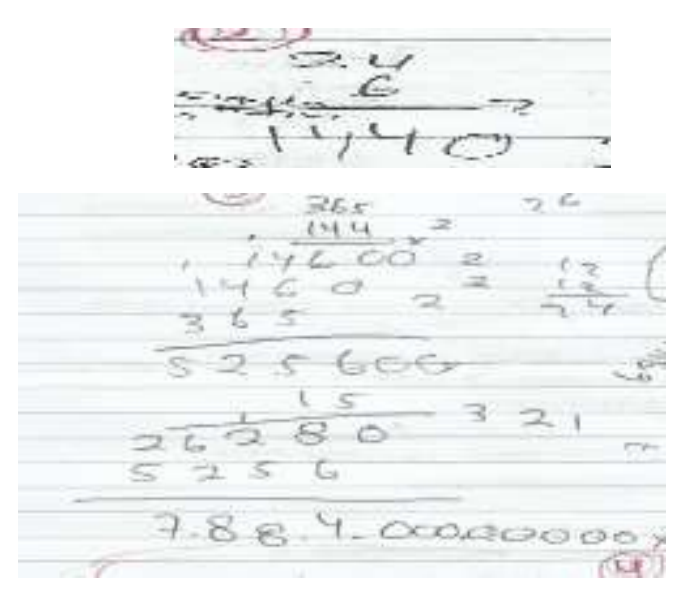

Gambar 1

Selanjutnya siswa menyelesaikan soal banyaknya sampah yang tidak di daur ulang sehingga mereka mengalikan banyaknya sampah kantong plastik dalam satu tahun 
dengan 50\% untuk mendapatkan banyaknya sampah plastik yang tidak didaur ulang sehingga banyaknya samapah kantong plastik yaitu $788.400 .000 .000 \times 50 \%=$ 394.200.000.000. Setelah itu, untuk mendapatkan sampah plastik yang tidak didaur ulang, siswa mengurangi banyaknya sampah kantong plastik dengan banyaknya sampah kantong plastik yang di daur ulang menjadi 788.400.000.000 - 394.200.000.000 = 394.200.000.000. hasil pekerjaan siswa seperti gambar di bawah ini.

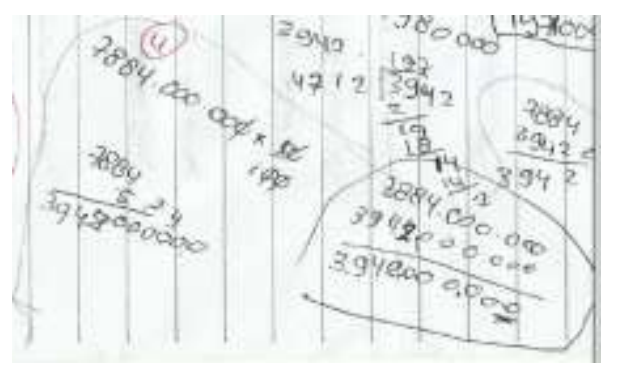

Gambar 2

Selanjutnya siswa menyajikannya dalam tabel seperti gambar di bawah ini:

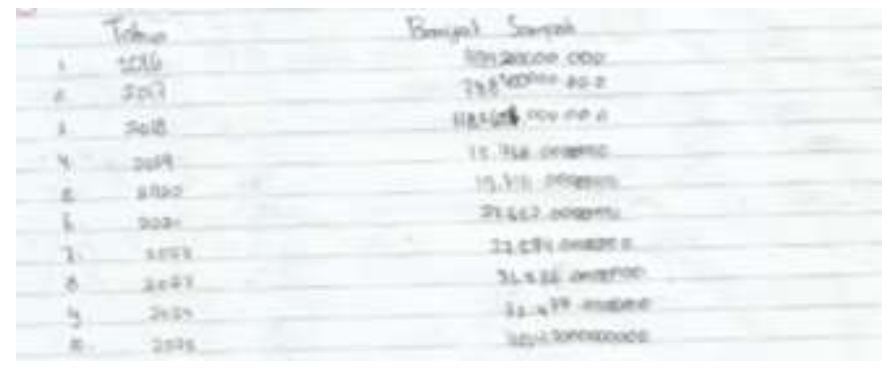

Gambar 3

Setelah membuat tabel, siswa pada kelompok pertama mendiskusikan bagaimana membuat model dengan cara mengurutkan $1-5$ terlebih dahulu dan yang ditanyakan pada tahun ke 5. Langkah pemikiran dalam kelompok tersebut adalah banyaknya sampah pada tahun 1 ditambah dengan tahun yang ditanyakan yakni tahun ke 5 dikali selisih tiap tahun dikurangi banyaknya sampah kantong plastik tahun 1 dikali selisih tiap tahun. Namun, disini ditemukan lagi letak kesalahan siswa dalam menghitung tahun ke 5. Sehingga hasil yang diperoleh tidak sesuai dengan tabel. Kemudian pada Gambar 7 dapat dilihat bahawa siswa mengerjakan lagi dan yang ditanyakan pada tahun ke 10. Sama hal dengan cara pada Gambar 6 sehingga banyaknya sampah kantong plastik yang diperoleh sama dengan tabel yang dibuat yakni banyaknya 
sampah kantong plastik pada tahun 2025 sebesar 394.200.000.0000 untuk setiap menitnya. Hasil dari diskusi kelompok 1 untuk memodelkan permasalahan pada berita tersebut mula - mula memisalkan $1,2,3 \ldots=n$ sehingga banyaknya sampah kantong plastik pada tahun 1 ditambah tahun yang ditanyakan $n$ dikalikan selisih sampah tiap tahun dikurangi tahun $n$ dikalikan selisih tiap tahun. Seperti pada Gambar 4 dibawah ini.

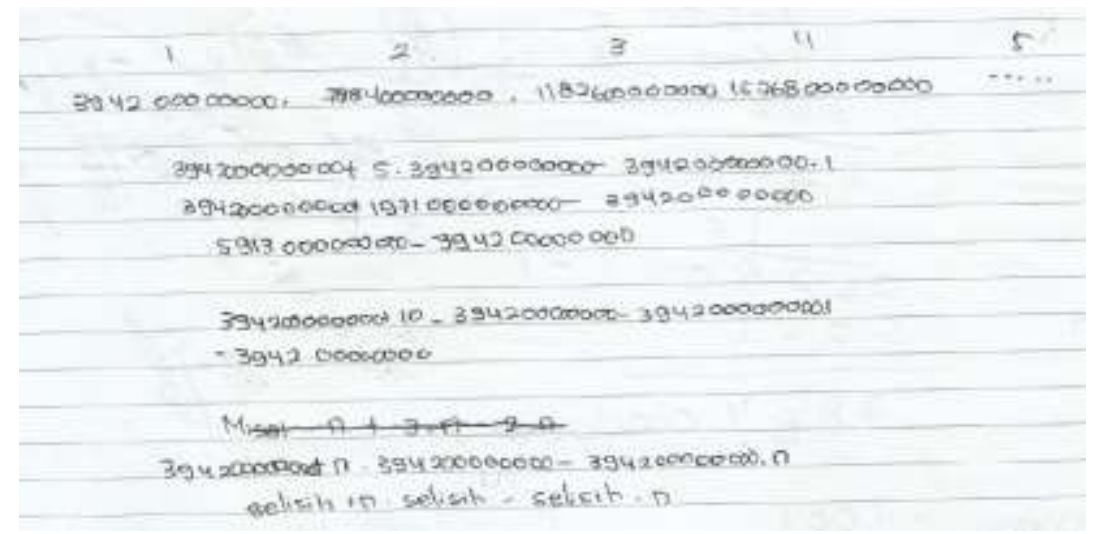

Gambar 4

Kelompok kedua (S4, S5, S6) menyelesaikan LKS dengan menjelaskan arti dari kalimat lebih dari 1 juta kantong plastik digunakan dalam satu menit yaitu dengan memisalkan 1 menit masyarakat Indonesia menggunakan 1.100.000 kantong plastik. Setelah menentukan penggunaan kantong plastik dalam 1 menit, siswa menghitung banyak kantong plastik yang tidak di daur ulang dalam 1 menit, 1 jam, 1 hari dan 1 tahun seperti yang ditunjukan pada gambar di bawah ini.

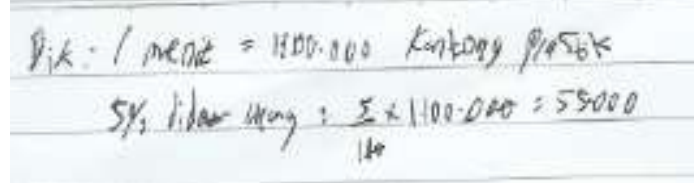

Gambar 5

Dari proses penyelesaian, tampak bahwa siswa cenderung menulis nilai yang merupakan hasil dari perhitungan matematis,tanpa memaknai nilai dari hasil perhitungan secara matematis. Selanjutnya dalam menentukan banyaknya sampah pada tahun 2025, para siswa mencoba untuk menyajikannya dalam bentuk grafik walaupun tidak secara lengkap dan dari grafik siswa menentukan tahun 2016 sebagai tahun awal 
lalu tahun selanjutnya dipilih 3 tahun kemudian. Seperti pada gambar di bawah ini.

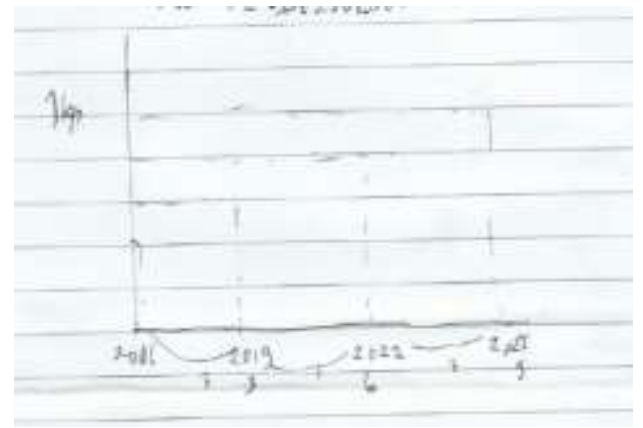

Gambar 6

Berdasarkan hasil wawancara, penentuan 3 tahun selanjutnya digunakan untuk memudahkan siswa menentukan banyaknya kantong plastik yang tidak di daur ulang pada tahun 2025. Kemudian siswa menetukan banyaknya kantong plastik yang tidak di daur ulang dengan menyajikan dalam bentuk tabel seperti pada gambar di bawah ini.

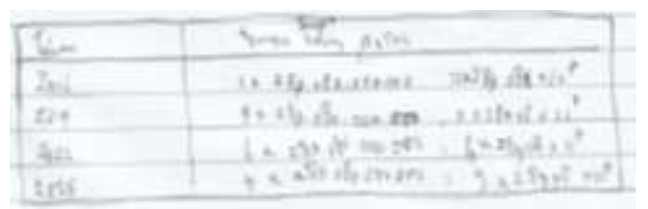

Gambar 7

Setelah menyajikan dalam bentuk tabel, siswa pada kelompok dua membuat kesimpulan bahwa untuk menghitung banyaknya kantong plastik yang tidak didaur ulang pada tahun tertentu adalah

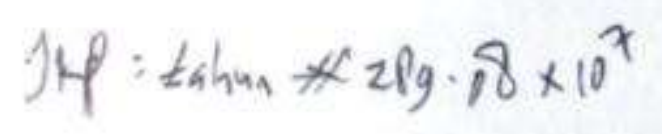

Gambar 8

Tanggapan siswa terhadap kegiatan pemodelan di atas, sebagai berikut:

\section{Kelompok 1}

1. Belajar matematika dengan menggunakan masalah lingkungan sangat menarik, walaupun masih kesulitan dalam memahami persoalan yang diberikan.

2. Untuk mengatasi banyaknya sampah plastik, mereka akan berusaha untuk mengurangi penggunaan sampah kantong plastik dan melatih diri untuk mendaur ulang sampah plastik. 


\section{Kelompok 2}

1. Belajar matematika dari berita merupakan pengalaman baru.

2. Merasa kaget dengan kenyataan bahwa dalam setiap menit, masyarakat indonesia banyak menghasilkan sampah plastik, oleh karena itu mereka akan berusaha untuk mengurangi penggunaan kantong plastik.

Sedangkan niat-niat yang hendak mereka lakukan untuk mengatasi permasalahan tersebut yaitu:

1. Mengurangi penggunaan kantong plastik dengan menggunakan kantong plastik dua kali atau lebih.

2. Membawa keranjang belanja ketika hendak berbelanja

3. Mendaur ulang sampah kantong plastik menjadi kerajinan tangan yang memiliki nilai beli.

4. Menggunakan daun pisang sebagai pengganti pembungkus nasi atau jajanan di sekolah.

\section{SIMPULAN DAN SARAN}

Pembelajaran tentang masalah lingkungan dan proses pemodelan matematika merupakan pengalaman baru yang dialami oleh 6 siswa SMP Turi. Pembelajaran dengan membahas sampah kantong plastik yang erat kaitan dengan lingkungan sekitar, membantu siswa dalam upaya menyadarkan siswa untuk menjaga lingkungan sekitar. Selain itu juga, pembelajaran dengan menggunakan masalah lingkungan sekitar sangat menarik untuk dikembangkan agar siswa tidak merasa bosan dalam pembelajaran matematika. Pemodelan yang dirancang oleh siswa ada 2 bentuk yaitu membuat model dengan melihat selisih hasil tiap tahun dari tabel dan membuat model dari perhitungan setiap tiga tahun berturut-turut. Dari hasil pembahasan keenam siswa tersebut dapat disimpulkan bahwa strategi maupun cara berpikir analisis dalam mencoba memecahkan problem yang diminta mempunyai cara berbeda untuk membuat pemodelan matematis. Hal tersebut berdampak pada peningkatan kemampuan siswa dan meningkatkan kesadaran siswa terhadap permasalahan lingkungan sampah kantong plastik.

\section{DAFTAR RUJUKAN}

Houston, SJ Lamon, W A Parker, dan S K. 2003. Mathematical Modelling : A Way Of Life. Horwood Publishing Chicchester : England 
Tri Wahyuni (2016). Indonesia Penyumbang Sampah Plastik Terbesar Ke-Dua Dunia. Diakses tanggal 23 Februari 2016, pada http://www.cnnindonesia.com/gayahidup/20160222182308-277-112685/indonesia-penyumbang-sampah-plastikterbesar-ke-dua-dunia/

Muhlisrarini, dan H.M. Ali Hamzah. 2013. Perencanaan dan Strategi Pembelajaran Matematika. PT Raja Grafindo Persada : Jakarta. 